\title{
Associations of FoxP3 gene polymorphisms with severe recurrent respiratory papillomatosis in Korean patients
}

\author{
Tack-Kyun Kwon ${ }^{1}$, Eun Jae Chung ${ }^{1}$, Nuri Lee ${ }^{2}$, Eun Youn Roh ${ }^{2}$ and Eun Young Song ${ }^{2^{*}}$
}

\begin{abstract}
Background: FoxP3 is the most dependable marker for regulatory T cells which play a major role in immune tolerance. Foxp3 gene polymorphisms were associated with various autoimmune diseases and clearance of viral infections. We studied the association of Foxp3 polymorphisms in severe RRP patients.

Methods: A total of 30 Korean severe RRP patients and 195 healthy controls were enrolled. Foxp3 polymorphisms (rs5902434 del/ATT, rs3761548 C/A, rs3761549 C/T, and rs2232365 G/A) were determined by PCR and sequencing.

Results: Genotype frequencies (GF) of rs5902434 ATT/ATT and rs2232365 GG were significantly decreased in female RRP patients than controls ( $0.0 \%$ vs $23.0 \%, p=0.039, \mathrm{OR}=9.4$ for both).

Conclusions: We showed that Foxp3 polymorphism of rs5902434 and rs2232365 could be an important protective factor in the susceptibility of severe RRP in female Koreans. Further studies on larger number of patients and other ethnic groups are needed to clarify the association.
\end{abstract}

Keywords: Disease susceptibility, Foxp3, Human papilloma virus, Recurrent respiratory papillomatosis, Single nucleotide polymorphism

\section{Background}

Regulatory $\mathrm{T}$ (Treg) cells are involved in diseases characterized by dysregulated peripheral tolerance, such as autoimmune diseases and viral reactivation. Forkhead box P3 (FoxP3) is a transcription factor that regulates Treg development and function, and is still the most reliable marker for Treg [1].

Recurrent respiratory papillomatosis (RRP) is a rare benign neoplasm of the larynx and trachea characterized by frequent recurrences of papilloma of the airway with significant morbidity. Although it is caused by human papillomavirus (HPV) types 6 and 11, it is unclear why only a very small fraction of HPV-exposed subjects develop RRP [2]. In RRP patients, complete eradication of HPV is rare, which implicates defects in the host cellmediated immune response [3]. Recently, the increase of Treg in papilloma tissue but exhaustion and chronic

\footnotetext{
*Correspondence: eysong1@snu.ac.kr

${ }^{2}$ Department of Laboratory Medicine, Seoul National University College of

Medicine, 101 Daehak-ro, Jongno-gu, Seoul 03080, South Korea

Full list of author information is available at the end of the article
}

activation of Treg have been reported [4]. Foxp3 gene polymorphisms in promoter region could affect the function and quantity of Foxp3 molecule, which results in defects in Treg function, have been associated with various autoimmune disease and clearance of viral infections $[5,6]$. In this study, we analyzed the association of four Foxp3 polymorphisms (rs5902434 del/ATT, rs3761548 C/A, rs3761549 C/T, and rs2232365 G/A) in promoter region in Korean severe RRP patients.

\section{Methods}

RRP patients and control subjects

A total of 30 patients (26 adults and 4 children) who underwent surgery for severe RRP in the period from Feb 2010 to Dec 2010 at Seoul National University Hospital were included in this study. The mean age of patients was 41.2 years ( $4-80$ years). Clinical severity was determined by the extent of disease at the time of surgery and the frequency of recurrence as previously described [7]. At each surgery, the clinical and anatomical scores were documented to yield a total score according to previously 
suggested staging system [8]. The mean growth rate of multiple surgeries was used to define the overall severity score for an individual patient. An overall disease severity score of $\geq 0.06$, or more than three surgeries in the previous 12 months, or tracheal extension, was defined as severe RRP [7]. Out of 15 female RRP patients, four patients had medical history of immune-related disorder; Pityriasis lichenoides chronica, Immune chronic urticaria, Erysipelas, and allergic reaction to various drugs such as NSAIDs, cefazolin, and radiocontrast agent, respectively. Out of 15 male RRP patients, one patient had allergic history to radiocontrast agent. Ethylenediamine tetraacetic acid (EDTA) blood samples were collected at the time of operation. Informed consents were obtained from all patients. This study was approved by the institutional review board at our institution (IRB No. 1403-018-562). For normal controls, 195 healthy Koreans were used.

\section{Genotyping of FoxP3 gene polymorphisms}

In 30 patients, genomic DNA was prepared from peripheral blood using a QIAamp DNA Blood Mini Kit (Qiagen, Valencia, CA). Four FoxP3 polymorphisms (rs5902434 del/ATT, rs3761548 C/A, rs3761549 C/T and rs2232365 G/A) were analyzed by PCR-sequencing (Table 1). PCR was performed with a total of $40 \mathrm{uL}$ reaction mixture containing $40 \mathrm{ng} \mathrm{DNA}, 2 \mathrm{uL}$ of 10 pmole/uL concentration of each primer, $0.8 \mathrm{uL}$ of each $10 \mathrm{mM}$ dNTP mix, $2.0 \mathrm{mM}$ $\mathrm{MgCl}_{2}$ and 1.0 U Taq DNA polymerase (Roche applied science, Basel, Switzerland) with $4 \mathrm{uL}$ of $10 \mathrm{X}$ reaction buffer. Protocol consisted of an initial denaturation step at 95 ${ }^{\circ} \mathrm{C}$ for $5 \mathrm{~min}$; 30 cycles of $30 \mathrm{~s}$ denaturation step at $95{ }^{\circ} \mathrm{C}$, $30 \mathrm{~s}$ annealing step at each annealing temperature (Table 1) and $30 \mathrm{~s}$ extension step at $72{ }^{\circ} \mathrm{C}$, and with a 5 min final extension step at $72{ }^{\circ} \mathrm{C}$.

Five $\mu \mathrm{L}$ of the PCR products were mixed with $2 \mu \mathrm{L}$ of ExoSAP-IT PCR Clean Up (Affymetrix, Inc., Santa Clara, CA, USA) and were incubated at $37{ }^{\circ} \mathrm{C}$ for $15 \mathrm{~min}$ and $80{ }^{\circ} \mathrm{C}$ for $15 \mathrm{~min}$. Four $\mathrm{uL}$ of BigDye Terminator Ready Reaction Mix (Life technologies, Grand Island, NY, USA), $1 \mathrm{uL}$ of 5 pmole/uL sequencing primer, and $4 \mathrm{uL}$ of deionized water were added to $1 \mathrm{uL}$ of purified PCR product with 30 thermal cycles $\left(96{ }^{\circ} \mathrm{C}\right.$ for $10 \mathrm{~s}, 50{ }^{\circ} \mathrm{C}$ for $5 \mathrm{~s}$, and $60{ }^{\circ} \mathrm{C}$ for $4 \mathrm{~min}$ ). Two uL of $3 \mathrm{M}$ sodium acetate/EDTA buffer ( $\mathrm{pH} 4.6)$ and $25 \mathrm{uL}$ of absolute EtOH were added. After vigorous vortexing and centrifugation at $2000 \mathrm{~g}$ for $30 \mathrm{~min}$, supernatant was removed. Addition of $50 \mathrm{uL}$ of $80 \% \mathrm{EtOH}$ and centrifugation at $2000 \mathrm{~g}$ for $5 \mathrm{~min}$ were repeated twice. Fifteen $\mathrm{uL}$ of $\mathrm{Hi}$ Di Formamide (Life technologies, Grand Island, NY, USA) was added and heated for $4 \mathrm{~min}$ at $95^{\circ} \mathrm{C}$. Samples were loaded on ABI 3730XL DNA analyzer (Applied Biosystems, Foster City, CA, USA). The electropherograms were processed using Chromas Lite 2.1.1 (Technelysium Pty Ltd., Brisbane, Australia).

\section{Statistical analysis}

The SNPs were selected based on CHB haplotype data using the HAPMAP database (http://www.hapmap.org). Observed genotype frequency was tested by HardyWeinberg equilibrium (HWE) on males and females separately because FoxP3 gene is located on $X p 11.23$. Odds ratio $(\mathrm{OR})$ and confidence interval $(\mathrm{CI})$ were calculated. Frequencies of the genotypes of four FoxP3 polymorphisms in RRP patient and controls were compared by Fisher's exact test or Chi-square test as appropriate, and also on males and females separately, because FoxP3 gene maps to $\mathrm{X} p 11.23$. The level of significance was set at $p<0.05$, and odds ratios (ORs) with $95 \%$ confidence intervals (CI) were calculated for those comparisons showing significant $p$ values.

\section{Results}

Genotype frequencies (GF) of FoxP3 polymorphisms in RRP patients and controls are presented in Table 2. GF of FoxP3 polymorphisms in male RRP patients are not different from those in controls. GF of rs5902434 del/ ATT were significantly increased in female RRP patients than controls $(66.7 \%$ vs $43.0 \%, p=0.043$, OR $=3.1[95 \%$ CI, 1.0-9.7]). GF of rs5902434 ATT/ATT were significantly decreased in female RRP patients than controls (0.0\% vs $23.0 \%, p=0.039$, OR $=9.4$ [95\% CI, 1.1-163.1]). GF of rs2232365 AG were significantly increased in

Table 1 Sequencing primers

\begin{tabular}{llll}
\hline Polymorphism & Primer & $5^{\prime}-3^{\prime}$ & Length (bps) \\
\hline rs5902434 & FP3-1 F & CTGCTCTCCCCTACCAGATG & $196 \mathrm{bp}$ \\
del/ATT & FP3-1R & CCCTGCCCATGCATTAAGTA & $50^{\circ} \mathrm{C}$ \\
rs3761548 & FP3-2 F & TTGTCTACTCCACGCCTCTCC & $373 \mathrm{bp}$ \\
C/A & FP3-2R & TGCCTCCATCATCACCACG & $60{ }^{\circ} \mathrm{C}$ \\
rs3761549 & FP3-4 F & GTCCTCTCCACAACCCAAGA & $250 \mathrm{bp}$ \\
C/T & FP3-4R & CAGATTTTCCGCCATTGAC & $60{ }^{\circ} \mathrm{C}$ \\
rs2232365 & FP3-3 F & GAGGGCTTCAAGGTGAGGA & $371 \mathrm{bp}$ \\
G/A & FP3-3R & GGGAGTTGGATTGGGTGCA & $60{ }^{\circ} \mathrm{C}$ \\
\hline
\end{tabular}

bps base pairs, $A T$ annealing temperature 
Table 2 Associations of FOXp3 polymorphisms with RRP

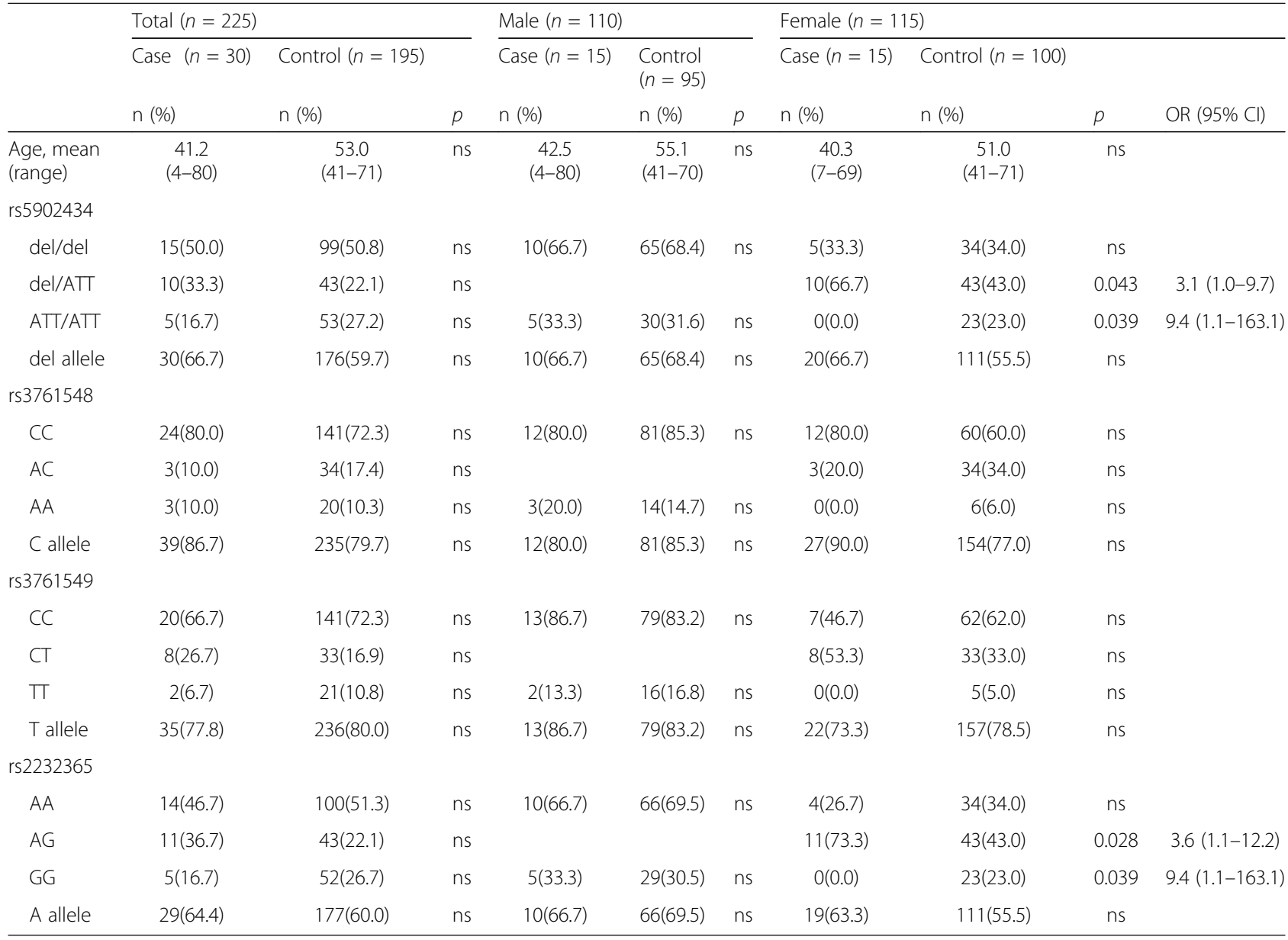

$R R P$ recurrent respiratory papillomatosis, $\mathrm{OR}$ odds ratio, $\mathrm{Cl}$ confidence interval

female RRP patients than controls $(73.3 \%$ vs $43.0 \%, p=$ $0.028, \mathrm{OR}=3.6[95 \% \mathrm{CI}, 1.1-12.2]) . \mathrm{GF}$ of rs2232365 GG was significantly decreased in female RRP patients than controls $(0.0 \%$ vs $23.0 \%, 761548, p=0.039$, OR $=$ 9.4 [95\% CI, 1.1-163.1]). GF of rs3761548 A/C and rs3761549 showed no statistically significant difference between RRP patients and controls.

\section{Discussion}

It is still not known why only a very small proportion of HPV-exposed subjects have recurrent respiratory papillomatosis (RRP). The local HPV-specific immune responses that allow chronic HPV-6 and -11 infections in RRP patients was suggested. As a possible mechanism, the dominance of Th2-like cytokine (IL-4 and IL-10) responses and decreased secretion of IFN- $\gamma$ were reported by peripheral blood mononuclear cells (PBMC) exposed to autologous papilloma tissues in patients with RRP [9]. Recently, impaired function of Tregs was also suggested as a possible mechanism for developing RRP [4].

FoxP3 is crucial regulatory factor for the development and function of Tregs. Polymorphisms have been reported in various regions of the FOXP3 gene, including the promoter, intron and exon regions. Promoters are relevant to initiating transcription and are therefore might harbor functionally involved polymorphisms [10]. Polymorphisms of FOXP3 gene promoter may affect the function or quantity of Treg, resulting in various autoimmune diseases. Therefore, Foxp3 gene promoter polymorphisms were associated with various autoimmune diseases [5] and CMV infection in pediatric allogeneic hematopoietic stem cell transplantation [11].

In our study, rs3761548, which was frequently reported to be associated with various diseases [5] showed no association with RRP patients. However, rs5902434 ATT/ATT genotype and rs2232365 GG genotype were significantly decreased in female RRP patients than controls. The rs5902434 del/del genotype was significantly associated with lupus nephritis in Taiwanese [12], and preeclampsia in Chinese [6], but, was not associated with allergic rhinitis [13] and unexplained recurrent spontaneous abortion [14]. The rs2232365 GG genotype was associated with unexplained recurrent spontaneous abortion [14] in Chinese, but showed no association with 
psoriasis [15] and Crohn's disease [16]. Polymorphisms of FOXP3 gene promoter may change the binding specificity of transcription factors and are related to initiating transcription, therefore, may affect the function or quantity of Treg [17], resulting in various autoimmune diseases. The reason why the impacts are various in different disease and ethnic groups should be further elucidated. In our study, the associations of FoxP3 polymorphisms were observed only in female RRP patients. FoxP3 gene is located on Xp11.23. Lyonization of Xchromosome results in only two phenotypes for each polymorphism, which might affect the pathogenesis of RRP in females, should be also clarified in further studies.

Interestingly, for both rs5902434 and rs2232365, the frequencies of heterozygote were significantly higher in female RRP patients than controls. The unusual associations of heterozygote of FoxP3 rs3761548 (AC genotype) have been reported in allergic rhinitis [13] and Graves' disease [18]. The mechanism is not clear yet, but the heterozygosity of Foxp3 polymorphism itself may have unknown but considerable effects on the pathogenesis of various autoimmune disease and also on RRP.

\section{Conclusions}

In conclusion, polymorphisms of FoxP3 rs5902434 and rs2232365 were associated with female RRP in Koreans. These results suggest the possible role of Foxp3 polymorphisms in immune tolerance of HPV infection in RRP pathogenesis. Further studies in larger number of patients including other ethnic groups are needed.

\section{Abbreviations}

EDTA: Ethylenediamine tetraacetic acid; FoxP3: Forkhead box P3; GF: Genotype frequencies; HPV: Human papillomavirus; PBMC: Peripheral blood mononuclear cells; RRP: Recurrent respiratory papillomatosis; Treg: Regulatory $T$

\section{Acknowledgements}

Not applicable.

\section{Funding}

This study was supported by a grant number 0320150180 from the SNUH research fund.

\section{Availability of data and materials}

Data can be requested by contacting the corresponding author.

\section{Authors' contributions}

$T K, E J, N L, E Y$, and $E Y$ have participated in the concept and design, analysis and interpretation of data, drafting and/or revising the manuscript, and have approved the manuscript as submitted.

\section{Competing interests}

The authors declare that they have no competing interests.

\section{Consent for publication}

We got informed consents for our study from all participating patients.

\section{Publisher's Note}

Springer Nature remains neutral with regard to jurisdictional claims in published maps and institutional affiliations.

\section{Author details}

'Department of Otolaryngology-Head and Neck Surgery, Seoul National University College of Medicine, Seoul, South Korea. ${ }^{2}$ Department of Laboratory Medicine, Seoul National University College of Medicine, 101 Daehak-ro, Jongno-gu, Seoul 03080, South Korea.

Received: 19 December 2016 Accepted: 13 March 2017 Published online: 15 March 2017

\section{References}

1. Fontenot JD, Gavin MA, Rudensky AY. Foxp3 programs the development and function of CD4 + CD25+ regulatory T cells. Nat Immunol. 2003;4:330-6.

2. Abramson AL, Steinberg BM, Winkler B. Laryngeal papillomatosis: clinical histopathologic and molecular studies. Laryngoscope. 1987;97:678-85.

3. Bonagura VR, Hatam LJ, Rosenthal DW, de Voti JA, Lam F, Steinberg BM, et al. Recurrent respiratory papillomatosis: a complex defect in immune responsiveness to human papillomavirus-6 and -11. APMIS. 2010;118:455-70.

4. Hatam LJ, Devoti JA, Rosenthal DW, Lam F, Abramson AL, Steinberg BM, et al. Immune suppression in premalignant respiratory papillomas: enriched functional CD4 + Foxp3+ regulatory T cells and PD-1/PD-L1/L2 expression. Clin Cancer Res. 2012;18:1925-35.

5. Oda JM, Hirata BK, Guembarovski RL, Watanabe MA. Genetic polymorphism in FOXP3 gene: imbalance in regulatory T-cell role and development of human diseases. J Genet. 2013;92:163-71.

6. Chen X, Gan T, Liao Z, Chen S, Xiao J. Foxp3 (-/ATT) polymorphism contributes to the susceptibility of preeclampsia. PLoS One. 2013;8, e59696.

7. Bonagura VR, Vambutas A, DeVoti JA, Rosenthal DW, Steinberg BM, Abramson $\mathrm{AL}$, et al. HLA alleles, IFN-gamma responses to HPV-11 E6, and disease severity in patients with recurrent respiratory papillomatosis. Hum Immunol. 2004;65:773-82.

8. Derkay CS, Malis DJ, Zalzal G, Wiatrak BJ, Kashima HK, Coltrera MD. A staging system for assessing severity of disease and response to therapy in recurrent respiratory papillomatosis. Laryngoscope. 1998;108:935-7.

9. DeVoti JA, Steinberg BM, Rosenthal DW, Hatam L, Vambutas A, Abramson $A L$, et al. Failure of gamma interferon but not interleukin-10 expression in response to human papillomavirus type $11 \mathrm{E} 6$ protein in respiratory papillomatosis. Clin Diag Lab Immunol. 2004;11:538-47.

10. Hoogendoorn B, Coleman SL, Guy CA, Smith K, Bowen T, Buckland PR, et al. Functional analysis of human promoter polymorphisms. Hum Mol Genet. 2003;12:2249-54.

11. Piao Z, Kim HJ, Choi JY, Hong CR, Lee JW, Kang HJ, et al. Effect of FOXP3 polymorphism on the clinical outcomes after allogeneic hematopoietic stem cell transplantation in pediatric acute leukemia patients. Int Immunopharmacol. 2016;31:132-9.

12. Lin YC, Lee JH, Wu AS, Tsai CY, Yu HH, Wang LC, et al. Association of singlenucleotide polymorphisms in FOXP3 gene with systemic lupus erythematosus susceptibility: a case-control study. Lupus. 2011;20:137-43.

13. Zhang L, Zhang Y, Desrosiers M, Wang C, Zhao Y, Han D. Genetic association study of FOXP3 polymorphisms in allergic rhinitis in a Chinese population. Hum Immunol. 2009;70:930-4.

14. Wu Z, You Z, Zhang C, Li Z, Su X, Zhang X, et al. Association between functional polymorphisms of Foxp3 gene and the occurrence of unexplained recurrent spontaneous abortion in a Chinese Han population. Clin Dev Immunol. 2012;2012:896458.

15. Gao L, Li K, Li F, Li H, Liu L, Wang L, et al. Polymorphisms in the FOXP3 gene in Han Chinese psoriasis patients. J Dermatol Sci. 2010;57:51-6.

16. Park O, Grishina I, Leung PS, Gershwin ME, Prindiville T. Analysis of the Foxp3/scurfin gene in Crohn's disease. Ann N Y Acad Sci. 2005;1051:218-28.

17. Hanel SA, Velavan TP, Kremsner PG, Kun JF. Novel and functional regulatory SNPs in the promoter region of FOXP3 gene in a Gabonese population. Immunogenetics. 2011;63:409-15.

18. Inoue N, Watanabe N, Morita M, Tomizawa R, Akamizu T, Tatsumi K, et al. Association of functional polymorphisms related to the transcriptional level of FOXP3 with prognosis of autoimmune thyroid diseases. Clin Experimental Immunol. 2010;162:402-6. 